\title{
Sensitivity and Specificity of Serology, Histopathology, and Molecular Tests in the Detection of Leptospirosis from Slaughtered Cattle in Indonesia
}

\author{
Asih Rahayu ${ }^{1}$, Yos Adi Prakoso ${ }^{1}$, Kurnia Desiandura ${ }^{1}$, and Yuli Purwandari Kristianingrum ${ }^{2 *}$ \\ ${ }^{1}$ Faculty of Veterinary Medicine, University of Wijaya Kusuma Surabaya, East Java, 60225, Indonesia \\ ${ }^{2}$ Deptartment of Pathology, Faculty of Veterinary Medicine, University of Gadjah Mada, Yogyakarta, 55281, Indonesia \\ *Corresponding author's Email: yuli.purwandari.kristianingrum@gmail.com; (DORCiD: 0000-0002-0245-7632
}

\begin{abstract}
Leptospira spp. is a pathogenic bacteria that causes leptospirosis in humans and cattle. The World Health Organization (WHO) recommends the microscopic agglutination test (MAT) as the laboratory gold standard in the detection of leptospirosis. However, the limitation of MAT triggers the laboratory technicians to develop alternative laboratory tests against leptospirosis. The current study aimed to compare the sensitivity and specificity of histopathology special stain using modified Gram staining (MGS) and molecular test using reverse transcriptasepolymerase chain reaction (RT-PCR), compared to the MAT for Leptospira spp. detection in cattle. This study used a total of 38 serum and 38 kidney samples from the cattle slaughtered in the Sidoarjo slaughterhouse, Indonesia. The collected serum samples were tested against MAT and RT-PCR. The kidneys were processed for histopathology using MGS. The result indicated that $16(42.10 \%)$ of the tested samples were positive against MAT, $6(15.78 \%)$ were positive against MGS, and $18(47.36 \%)$ were positive against RT-PCR. The RT-PCR indicated better sensitivity and lower specificity, compared to MAT and MGS. The findings revealed that the RT-PCR is an appropriate laboratory test for detecting cattle leptospirosis with better sensitivity and specificity. Therefore, this method can be suggested to substitute MAT and overcome its limitations.
\end{abstract}

Keywords: Cattle, Histopathology, Leptospira spp., Molecular, Serology

\section{INTRODUCTION}

Leptospirosis in humans and animal is induced by Leptospira spp., a pathogenic bacteria which transmit from animal to human and vice versa (Haake and Levett, 2015). The rat's urine is the main source of transmission since the shedding of bacteria can be found until several days after excretion (Pui et al., 2017). The occurrence of leptospirosis has been mainly reported at low sanitary levels in urban areas and rural environments (Galan et al., 2021). However, it has become a neglected disease worldwide in the past few years (Roqueplo et al., 2019).

In Indonesia, rural areas are the main producers of daily products, such as milk, lamb, egg, and meat (Paul et al., 2019). Although cattle meat is the primary product monitored by food securities in Indonesia the majority of the cattle industries in Indonesia still have a conventional management system with poor sanitation. Poor sanitation triggers the presence of rats, and the presence of rats in the cattle industry can lead to the involvement of leptospirosis, which interferes with meat production industries (Daud et al., 2018). The prevalence of cattle leptospirosis in Indonesia is still limited and there are few reports related to leptospirosis (Widiasih et al., 2021).

The World Health Organization (WHO) recommends the microscopic agglutination test (MAT) as the laboratory gold standard in the detection of leptospirosis (Hartskeerl and Smythe, 2015). The MAT is the serology test that detects the antibody from the serum samples. However, it can not detect the disease in an early stage of Leptospira spp. infection either within the serum or tissue samples (Philip et al., 2020). Therefore, alternative laboratory tests are developed to overcome the MAT weakness.

Several studies have been conducted to cover the MAT limitation. The previous studies used immunoglobulin-M (IgM) as the target of detection. The IgM against Leptospira spp. is detected using several laboratory tests, including immune-chromatography (ICT, Niloofa et al., 2015; Rao et al., 2019), latex agglutination (LAT), and enzyme-linked immunosorbent assay (ELISA, Zin et al., 2019). Those tests generate varied sensitivity and specificity, compared to the gold standard. The ICT and ELISA generate similar results but with less sensitivity and specificity, compared to MAT (Niloofa et al., 2015; Rao et al., 2019). The LAT has better results, compared to ELISA, however, it is not applicable to the diagnosis of the early stage of infection (Zin et al., 2019). The instability of result in using an antibody as the target occurs because the antibody is not always produced in the first lineage of infection. 
The current study compared the obtained results with MGS and RT-PCR to those of MAT. The MGS can express the presence of bacteria within the tissue (Prakoso et al., 2020) and the RT-PCR elaborates the gene expression of the infectious agent from the samples (Zubach et al., 2020). The MGS and RT-PCR can similarly detect the agent directly within the samples and generate higher sensitivity and specificity. This study aimed to compare the sensitivity and specificity of histopathology special stain using MGS and molecular method using RT-PCR, compared to MAT for detection of Leptospira spp. in cattle.

\section{MATERIALS AND METHODS}

\section{Ethical approval}

The ethics for this study has been validated by the ethical clearance committee from the Faculty of Veterinary Medicine, University of Gadjah Mada, Yogyakarta, Indonesia (No. 045/EC-FKH/Int./2020). All the animal procedures during samples collection were monitored by the committee.

\section{Time and place of study}

All the research procedures have been conducted from November 2020 to April 2021. The samples of kidneys and serums were taken from Krian Slaughterhouse, Sidoarjo, East Java, Indonesia. The MAT and MGS were performed in the Integrated Laboratory, Faculty of Health Science, University of Muhammadiyah Sidoarjo, East Java, Indonesia. The RT-PCR was performed in the Station of Fish Quarantine for Quality Control and Safety of Fishery Product, Yogyakarta, Indonesia.

\section{Sample collection}

A total of 38 kidney and serum samples were collected from the operated slaughterhouse in Sidoarjo. The blood samples were taken through the jugular vein of the cattle and the kidney was taken after the cattle were slaughtered. The blood was stored inside a sterile serum tube. Further, the organ was fixed using $10 \%$ neutral buffer formalin. The serum samples were divided into two parts for the MAT and RT-PCR investigations. In contrast, the kidney tissue was processed for histopathology using MGS.

\section{Microscopic agglutination test procedure}

The MAT procedure was performed using the guideline in the previous study by Chirathaworn et al. (2014). The result of the test was described qualitatively as seropositive (for positive sample) and seronegative (for negative sample).

\section{Reverse transcriptase-polymerase chain reaction}

Lip132 was used as the primer for RT-PCR. The designed primer was forward 5' GGACGGTTTAGTCGATGGAA 3' and reverse 5' GGGAAAAGCAGACCAACAGA 3'. The RT-PCR was conducted following the demonstrated procedure in a previous study (Waggoner et al., 2014).

\section{Modified gram staining}

Before the MGS was performed, the kidney was dehydrated using xylene and graded alcohol $(70 \%, 80 \%, 90 \%$ of concentration). The sample was then blocked using paraffin. Further, the kidney was sectioned using a microtome (Leica, RM2235, China) in $5 \mu \mathrm{m}$ of thickness. The procedure of MGS was performed following the previous study (Becerra et al., 2016).

\section{Data analysis}

The data was recorded as positive and negative. The score 1 was given to the positive sample, and score 2 was for the negative sample. The statistical analysis was conducted using SPSS version 16 and Fisher's exact test. At last, the sensitivity and specificity were calculated using the following formulae of sensitivity = (number of positive samples/number of positive samples + number of false-positive samples $) \times 100 \%$; specificity $=$ (number of negative samples/number of negative samples + number of false-negative samples) $\times 100 \%$.

\section{RESULTS AND DISCUSSION}

From a total of 38 collected samples, $16(42.10 \%)$ were positive against MAT, $6(15.78 \%)$ were positive against MGS, and $18(47.36 \%)$ were positive against RT-PCR. The percentages of the positive and negative samples are presented in Table 1. Further, it was indicated that the result of each test in the current study varied based on the types and targets of the laboratory test. 
The data was then analyzed comparing the sensitivity of the MGS and RT-PCR to that of MAT. The reason for comparing the results to MAT is the fact that MAT is considered the gold standard for the detection of leptospirosis (Philip et al., 2020). The MGS showed the lowest sensitivity, compared to the other tests (Tables 2 and 3). While the specificity and sensitivity of MGS and RT-PCR have been compared with each other, it was indicated that there was a wide gap between the result of these tests. The wide gap in the present study showed that the RT-PCR had great sensitivity and low specificity, compared to the MGS (Table 4).

Table 1. Positive and negative results against Leptospira spp. from serum and kidney samples tested using several laboratory tests in Indonesia

\begin{tabular}{lccc}
\hline Test & Positive & Negative & Total \\
\hline Microscopic agglutination test & $16(42.10 \%)$ & $22(57.89 \%)$ & $38(100 \%)$ \\
Modified Gram staining & $6(15.78 \%)$ & $32(84.21 \%)$ & $38(100 \%)$ \\
Reverse transcriptase-polymerase chain reaction & $18(47.36 \%)$ & $20(52.63 \%)$ & $38(100 \%)$ \\
\hline
\end{tabular}

Table 2. Results of laboratory test using modified Gram staining and RT-PCR, compared to microscopic agglutination test for the detection of leptospirosis in cattle

\begin{tabular}{|c|c|c|c|c|c|c|}
\hline \multirow{2}{*}{ Test } & & \multicolumn{2}{|c|}{ Microscopic agglutination test } & \multirow{2}{*}{$X^{2}$} & \multirow{2}{*}{$r$} & \multirow{2}{*}{ Significance } \\
\hline & & + & - & & & \\
\hline \multirow{2}{*}{ Modified Gram staining } & + & 6 & 0 & \multirow{2}{*}{9.797} & \multirow{2}{*}{0.508} & \multirow{2}{*}{0.003} \\
\hline & - & 10 & 22 & & & \\
\hline \multirow{2}{*}{$\begin{array}{l}\text { Reverse transcriptase-polymerase chain } \\
\text { reaction }\end{array}$} & + & 16 & 2 & \multirow{2}{*}{30.707} & \multirow{2}{*}{0.899} & \multirow{2}{*}{0.000} \\
\hline & - & 0 & 20 & & & \\
\hline
\end{tabular}

Table 3. Results of laboratory test using modified Gram staining, compared to RT-PCR for detection of leptospirosis in cattle

\begin{tabular}{lcccccc}
\hline \multirow{2}{*}{ Test } & \multicolumn{2}{c}{$\begin{array}{c}\text { Reverse transcriptase-polymerase } \\
\text { chain reaction }\end{array}$} & $\boldsymbol{X}^{2}$ & $\boldsymbol{r}$ & Significance \\
\cline { 2 - 5 } Modified Gram staining & + & - & 0 & \multirow{2}{*}{7.917} & 0.456 & 0.007 \\
\hline
\end{tabular}

Table 4. Sensitivity and specificity of modified Gram staining and RT-PCR compared to microscopic agglutination test for detection of leptospirosis in cattle

\begin{tabular}{lcc}
\hline Test & Sensitivity & Specificity \\
\hline Modified Gram staining & $37.50 \%$ & $100.00 \%$ \\
Reverse transcriptase-polymerase chain reaction & $100.00 \%$ & $90.90 \%$ \\
\hline
\end{tabular}

The variability of the clinical signs in the host infected by Leptospira spp. triggers the development of new laboratory tools to enhance the diagnosis of this disease. The unintentional Leptospira spp. infection in humans generates common clinical signs, such as fever, which is similar to the common tropical diseases (De Brito et al., 2018). However, the cattle leptospirosis does not cause any clinical signs (asymptomatic) (Rajeev et al., 2014). The representation of asymptomatic clinical signs in cattle leptospirosis triggers the development of the other diagnostic tools. In the current study, the MAT was compared to the RT-PCR and MGS. All those methods have different targets of detection.

The MAT is a cheap detection method with high specificity, however, it is time-consuming with high crossreactivity, can neither detect limited antibodies within sera nor the early stage of leptospirosis. Besides, this method requires culture facilities (Budihal and Perwez, 2014). The other method used in this study is MGS, which is primarily used to detect the appearance of Leptospira spp. within the kidney tissue (Prakoso et al., 2020). The MGS can detect the Leptospira bacteria inside the tissue section. Unfortunately, it needs more time and has low sensitivity, it sometimes causes false-negative in case the observation is not conducted by the expert pathologist. As an invasive procedure, the MGS can only be performed in animals after death and cannot be used for detection at the early phase of leptospirosis (Prakoso et al., 2020). The molecular test used in the present study is RT-PCR. The RT-PCR generates high sensitivity and specificity, which rapidly confirm the result and can be used to detect the early phase of infection. Nevertheless, the RT-PCR still has some limitations, such as high cost, special laboratory equipment, qualified personnel, DNA extraction, which is the reason for not being used widely in the conventional laboratory (Budihal and Perwez, 2014). 
The study of leptospirosis from slaughtered cattle in the abattoir is necessary because the abattoir is the source of Leptospira and other zoonotic diseases transmission. The comparison of several laboratory tests in the current study intends to find out an appropriate method for the detection of leptospirosis that asymptomatically occurs in cattle. Furthermore, the findings of the present study indicated a high prevalence of leptospirosis in Sidoarjo slaughterhouse during six months. This study is eminent to be performed not only to observe the sensitivity and specificity of detection tools in the laboratory but also to observe the prevalence of this disease in the abattoir.

Furthermore, the MGS is less applicable as a detection method for leptospirosis since it has similar limitations regarding the result and interpretation to those of histopathological tests for the detection of Leptospira spp. infection. Another limitation is the deficiency in collected tissues which causes inappropriate reports in histopathological examinations (Jahn et al., 2020). The MGS is quite different from RT-PCR which generates better sensitivity for the detection of cattle leptospirosis. The RT-PCR has high specificity because it can be used to detect the soluble DNA within the plasma, either less or high in concentration (Compton, 2020). This method is applicable to express the presence of infection during the early active infection (Pellizzaro et al., 2019), and it does not need the culture in advance detection (Liu et al., 2019). Different from MGS and RT-PCR, the MAT catch the representation of antibody against Leptospira spp. within the serum (Chen et al., 2018), however, the presence of antibody cannot be used to describe the pathogenesis of disease clearly (Lessa-Aquino et al., 2017), and it sometimes causes cross-reactivity between various serovars (Andre-Fontaine and Triger, 2018).

The current study indicated different results of detection using the RT-PCR and MAT. The differences in results were due to the representation of detection limit between those tests. RT-PCR generates greater sensitivity than MAT. Redefining a new detection tool as the gold standard for leptospirosis examination is essential due to the limitations of MAT. According to the findings of the current study, RT-PCR is the most sensitive test in diagnosing cattle leptospirosis. However, the use of MAT as a gold standard may be caused by some reasons (Agampodi et al., 2016). Besides, the specificity of MAT is higher than the MGS. The other study supported the present finding regarding the specificity of MAT reaching 97.6\%, compared to others (Niloofa et al., 2015). Nevertheless, the MAT can produce falsepositive results while it is being used in an acute phase of infection. Present findings have indicated that MAT has lower sensitivity and specificity, compared to the RT-PCR that is similar to the previous report by Woods et al. (2018). Woods et al. (2018) described that the RT-PCR produces better sensitivity of reach $53.9 \%$, specificity of $99.6 \%$, and the MAT has sensitivity and specificity of $16 \%$. Accordingly, MGS has the lowest sensitivity due to the limitation of the observation area of analysis. None of the previous studies has described the sensitivity and specificity of the MGS and maybe this is the first exploration addressing the role of MGS in cattle leptospirosis detection.

The different detection methods have different targets which can cause greater gaps in the result. The RT-PCR is still considered the most sensitive and exact method. Furthermore, the minimum differences between MAT and RT-PCR regarding its sensitivity indicate that the MAT is still applicable as the laboratory test in diagnosing cattle leptospirosis and is cheaper than the RT-PCR. In addition, this study is not trying to introduce the best laboratory tools but justifies that the laboratory procedures employed in diagnosing the disease should be combined to overcome the limitations of each test.

\section{CONCLUSION}

All the laboratory tests used in the current study can be applied as the detection methods for leptospirosis in cattle. Further, the RT-PCR is the best alternative laboratory test with high sensitivity and specificity which can substitute the MAT. Each laboratory test has its own limitations and it is recommended to use a combination of tests to increase the accuracy and precision. In the future, it is necessary to develop other laboratory tests that are fast, cheap, and sensitive for Leptospira spp. detection. Finally, sequential monitoring regarding the cattle leptospirosis should be performed by the stakeholder to prevent zoonotic transmission of Leptospira spp.

\section{DECLARATIONS}

Authors' contribution

YAP and YPK designed and performed the laboratory procedure. AR and KD collected the specimens and performed analysis data. YAP wrote the draft of the article. YAP, AR, KD, and YPK performed manuscript revisions and approved the final version of the submitted manuscript.

\section{Competing interests}

The authors have not declared any conflict of interest.

\section{Ethical consideration}

Ethical issues (including plagiarism, consent to publish, misconduct, data fabrication and/or falsification, double publication and/or submission, and redundancy) have been checked by all the authors. 


\section{Acknowledgments}

The veterinarians and staff from Krian Slaughterhouse, Sidoarjo, Indonesia were acknowledged for providing the specimens in this study.

\section{REFERENCES}

Agampodi SB, Dahanayaka NJ, Nöckler K, Mayer-Scholl A, and Vinetz JM (2016). Redefining gold standard testing for diagnosing leptospirosis: Further evidence from a well-characterized, flood-related outbreak in Sri Lanka. The American Journal of Tropical Medicine and Hygiene, 95(3): 531-536. DOI: https://www.doi.org/10.4269/ajtmh.16-0033.

Andre-Fontaine G, and Triger L (2018). MAT cross-reactions or vaccine cross-protection: Retrospective study of 863 leptospirosis canine cases. Heliyon, 4(11): e00869. DOI: https://www.doi.org/10.1016/j.heliyon.2018.e00869.

Becerra SC, Roy DC, Sanchez CJ, Christy RJ, and Burmeister DM (2016). An optimized staining technique for the detection of Gram positive and Gram negative bacteria within tissue. BMC Research Notes, 9: 216. DOI: https://www.doi.org/10.1186/s13104-016$\underline{1902-0 .}$.

Budihal SV, and Perwez K (2014). Leptospirosis diagnosis: Competancy of various laboratory tests. Journal of Clinical and Diagnostic Research, 8(1): 199-202. DOI: https://www.doi.org/10.7860/JCDR/2014/6593.3950.

Chen HW, Lukas H, Becker K, Weissenberger G, Halsey ES, Guevara C, Canal E, Hall E, Maves RC, Tilley D et al. (2018). An improved enzyme-linked immunoassay for the detection of Leptospira-specific antibodies. The American Journal of Tropical Medicine and Hygiene, 99(2): 266-274. DOI: https://www.doi.org/10.4269/ajtmh.17-0057.

Chirathaworn C, Inwattana R, Poovorawan Y, and Suwancharoen D (2014). Interpretation of microscopic agglutination test for leptospirosis diagnosis and seroprevalence. Asian Pacific Journal of Tropical Biomedicine, 4: 162-164. DOI: https://www.doi.org/10.12980/APJTB.4.2014C580.

Compton SR (2020). PCR and RT-PCR in the diagnosis of laboratory animal infections and in health monitoring. Journal of the American Association for Laboratory Animal Science, 59(5): 458-468. DOI: https://www.doi.org/10.30802/AALAS-JAALAS20-000008.

Daud A, Fuzi N, Arshad MM, Kamarudin S, Mohammad W, Amran F, and Ismail N (2018). Leptospirosis seropositivity and its serovars among cattle in Northeastern Malaysia. Veterinary World, 11(6): 840-844. DOI: https://www.doi.org/10.14202/vetworld.2018.840-844.

De Brito T, Silva A, and Abreu P (2018). Pathology and pathogenesis of human leptospirosis: A commented review. Revista do Instituto de Medicina Tropical de Sao Paulo, 60: e23. DOI: https://www.doi.org/10.1590/s1678-9946201860023.

Galan DI, Roess AA, Pereira S, and Schneider MC (2021). Epidemiology of human leptospirosis in urban and rural areas of Brazil, 2000-2015. PLoS ONE, 16(3): e0247763. DOI: https://www.doi.org/10.1371/journal.pone.0247763.

Haake DA, and Levett PN (2015). Leptospirosis in humans. Current Topics in Microbiology and Immunology, 387: 65-97. DOI: https://www.doi.org/10.1007/978-3-662-45059-8_5.

Hartskeerl RA, and Smythe LD (2015). The role of leptospirosis reference laboratories. Current Topics in Microbiology and Immunology, 387: 273-288. DOI: https://www.doi.org/10.1007/978-3-662-45059-8_11.

Jahn SW, Plass M, and Moinfar F (2020). Digital pathology: Advantages, limitations and emerging perspectives. Journal of Clinical Medicine, 9(11): 3697. DOI: https://www.doi.org/10.3390/jcm9113697.

Lessa-Aquino C, Lindow JC, Randall A, Wunder E, Pablo J, Nakajima R, Jasinskas A, Cruz JS, Damião AO, Ney N et al. (2017). Distinct antibody responses of patients with mild and severe leptospirosis determined by whole proteome microarray analysis. PLoS Neglected Tropical Diseases, 11(1): e0005349. DOI: https://www.doi.org/10.1371/journal.pntd.0005349.

Liu HY, Hopping GC, Vaidyanathan U, Ronquillo YC, Hoopes PC, and Moshirfar M (2019). Polymerase chain reaction and its application in the diagnosis of infectious keratitis. Medical Hypothesis, Discovery and Innovation Ophthalmology Journal, 8(3): 152-155. Available at: http://www.ncbi.nlm.nih.gov/pmc/articles/pmc6778471/.

Niloofa R, Fernando N, De Silva NL, Karunanayake L, Wickramasinghe H, Dikmadugoda N, Premawansa G, Wickramasinghe R, De Silva HJ, Premawansa S et al. (2015). Diagnosis of leptospirosis: Comparison between microscopic agglutination test, igm-elisa and igm rapid immunochromatography test. PLoS ONE, 10(6): e0129236. DOI: https://www.doi.org/10.1371/journal.pone.0129236.

Paul CJ, Paul JE, and Anderson RS (2019). The local food environment and food security: The health behavior role of social capital. International Journal of Environmental Research and Public Health, 16(24): 5045. DOI: https://www.doi.org/10.3390/ijerph16245045.

Pellizzaro M, Martins CM, Yamakawa AC, Ferraz D, Morikawa VM, Ferreira F, Santos A, Biondo AW, and Langoni H (2019). Molecular detection of Leptospira spp. in rats as early spatial predictor for human disease in an endemic urban area. PLoS ONE, 14(5): e0216830. DOI: https://www.doi.org/10.1371/journal.pone.0216830.

Philip N, Affendy NB, Masri SN, Yuhana MY, Than L, Sekawi Z, and Neela VK (2020). Combined PCR and MAT improves the early diagnosis of the biphasic illness leptospirosis. PloS ONE, 15(9): e0239069. DOI: https://www.doi.org/10.1371/journal.pone.0239069.

Prakoso YA, Widyarini S, and Kurniasih K (2020). Histopathology of the organs from cattle with leptospirosis. Advances in Animal and Veterinary Sciences, 8(11): 1220-1224. DOI: http://www.dx.doi.org/10.17582/journal.aavs/2020/8.11.1220.1224.

Pui CF, Bilung LM, Apun K, and Su'ut L (2017). Diversity of Leptospira spp. in rats and environment from urban areas of Sarawak, Malaysia. Journal of Tropical Medicine, Article ID: 3760674. DOI: https://www.doi.org/10.1155/2017/3760674.

Rajeev S, Ilha M, Woldemeskel M, Berghaus RD, and Pence ME (2014). Detection of asymptomatic renal Leptospira infection in abattoir slaughtered cattle in southeastern Georgia, United States. SAGE Open Medicine, 2: 2050312114544696. DOI: https://www.doi.org/10.1177/2050312114544696. 
Rao M, Amran F, and Aqilla N (2019). Evaluation of a rapid kit for detection of igm against Leptospira in human. The Canadian Journal of Infectious Diseases and Medical Microbiology, Article ID: $5763595 . \quad$ DOI: https://www.doi.org/10.1155/2019/5763595.

Roqueplo C, Kodjo A, Demoncheaux JP, Scandola P, Bassene H, Diatta G, Sokhna C, Raoult D, Davoust B, and Mediannikov O (2019). Leptospirosis, one neglected disease in rural Senegal. Veterinary Medicine and Science, 5(4): 536-544. DOI: https://www.doi.org/10.1002/vms3.186.

Waggoner JJ, Balassiano I, Abeynayake J, Sahoo MK, Mohamed-Hadley A, Liu Y, Vital-Brazil JM, and Pinsky BA (2014). Sensitive real-time PCR detection of pathogenic Leptospira spp. and a comparison of nucleic acid amplification methods for the diagnosis of leptospirosis. PLoS ONE, 9(11): e112356. DOI: https://www.doi.org/10.1371/journal.pone.0112356.

Widiasih DA, Lindahl JF, Artama WT, Sutomo AH, Kutanegara PM, Mulyani GT, Widodo E, Djohan TS, and Unger F (2021). Leptospirosis in ruminants in yogyakarta, Indonesia: A serological survey with mixed methods to identify risk factors. Tropical Medicine and Infectious Disease, 6(2): 84. DOI: https://www.doi.org/10.3390/tropicalmed6020084.

Woods K, Nic-Fhogartaigh C, Arnold C, Boutthasavong L, Phuklia W, Lim C, Chanthongthip A, Tulsiani SM, Craig S, Burns MA et al. (2018). A comparison of two molecular methods for diagnosing leptospirosis from three different sample types in patients presenting with fever in Laos. Clinical Microbiology and Infection : The Official Publication of the European Society of Clinical Microbiology and Infectious Diseases, 24(9): 1017. DOI: https://www.doi.org/10.1016/j.cmi.2017.10.017.

Zin NM, Othman SN, Abd Rahman FR, and Abdul Rachman AR (2019). Evaluation of IgM LAT and IgM ELISA as compared to microscopic agglutination test (MAT) for early diagnosis of Leptospira sp. Tropical Biomedicine, 36(4): 1071-1080. Available at: https://www.msptm.org/files/Vol36No4/1071-1080-Zin-NM.pdf.

Zubach O, Semenyshyn O, Vasiuynets L, Velychko O, and Zinchuk A (2020). Application of PCR for specific diagnosis of leptospirosis in humans in Ukraine. Polish Journal of Microbiology, 69(4): 421-426. DOI: https://www.doi.org/10.33073/pjm2020-045. 